\title{
Opinion
}

\section{Health, Nutrition, and Economic Development in Africa}

\author{
Babatunde Omilola, PhD; N'doh A. Sanogo, PhD* \\ Public Health, Security and Nutrition Division, The African Development Bank Group, Avenue Joseph Anoma, 0 I BP I 387 Abidjan 0I, Côte d'Ivoire \\ *Corresponding author \\ N'doh A. Sanogo, PhD \\ Consultant for the Public Health, Security and Nutrition Division, The African Development Bank Group,Avenue Joseph Anoma, 0I BP I387 Abidjan 0I, \\ Côte d'Ivoire; E-mail: n.sanogo@afdb.org
}

Article information

Received: February 12 ${ }^{\text {th }}, 2020$; Revised: March $3^{\text {rd }}, 2020$; Accepted: March $3^{\text {rd }}, 2020$; Published: March $5^{\text {th }}, 2020$

Cite this article

Omilola B, Sanogo NA. Health, nutrition, and economic development in Africa. Public Health Open J. 2020; 5(I): I4- I6. doi: I0. I7I 40/PHOJ-5-I40

\section{PURPOSE |}

The purpose of this brief is to highlight the interconnections 1 between health, nutrition and economic development in Africa.

\section{What Does the Term “Well-Nourished Populations" Mean?}

The term "well-nourished populations" is the opposite of malnutrition. According to the World Health Organization (WHO), malnutrition refers to deficiencies, excesses or imbalance in a person's intake of energy and/or nutrients. The African continent faces the double burden of malnutrition (DBM) namely child undernutrition and adult/child obesity. ${ }^{1}$ Nutritional disparities and the DBM must be considered from a life course perspective. ${ }^{2}$

Research focusing on women of childbearing age living in socio-economically deprived circumstances has documented the intergenerational transmission of stunting. Maternal stunting, underweight, and gaining less weight than recommended during pregnancy are associated with intrauterine growth restriction, which has also been associated with increased risk of stunting for the baby. ${ }^{2,3}$ In fact, from conception to 15 -months of age, an infant is entirely dependent for its nutrition on the mother via the placenta and then ideally via exclusive breastfeeding. ${ }^{4}$ This period of 24-months is the most important and vulnerable in a child's life because it is during this period that the child's immune system and its physical and mental capacity develop. ${ }^{5}$ If undernutrition occurs during these first 1000-days, it might cause stunted growth and diminished function of the brain's grey matter, responsible for sensory perception, memory, decision-making and other function; and these consequences are irreversible. ${ }^{5}$ Despite a growing commitment to reducing levels of child undernutrition in Africa, there is still a lot to do. In 2016, there were around 58 million African children under the age of five who were too short for their age 13.9 million weighed too little for their size. ${ }^{5}$
With regard to obesity, we can say that obesity among women of childbearing age and children is increasing in Africa. Women who start pregnancy as overweight, are more likely to gain excessive weight during pregnancy, develop gestational diabetes, deliver large for gestational age or premature newborns, and are less likely to breastfeed. ${ }^{2,3}$ Among adults, obesity can lead to noncommunicable diseases such as diabetes, heart disease, stroke, and some cancers. ${ }^{2}$ Children born to overweight women have increased risks of developing obesity that persist as they mature. Women then pass to their children an increased risk of obesity that persists into later life, perpetuating the cycle. In 2017, 10.3 million African children were considered overweight., ${ }^{2,3}$

\section{Understanding the True Cost of Malnutrition}

Malnutrition costs African economies between 3 and 16\% of GDP annually. The conceptual framework (Figure 1) below explains the economic impacts of malnutrition in all its forms in four pathways.

Firstly, maternal mortality, linked to severe Anaemia, and reduced adult life expectancy, linked to obesity and related health complications, is additional manifestations of nutrition-mortality linkages. Preventable mortality represents a loss of human capital that affects families and whole communities.

The second pathway is ill health. Treatment costs are borne by families as well as by health insurance systems.

Thirdly, impaired physical growth (sub-optimal physical growth) reduces economic productivity lowered labour productivity or absenteeism from work.

Finally, impaired cognitive development resulting from poor nutrition from birth, especially during the first 1000-days of life,impairs cognitive development, delays school attendance and 


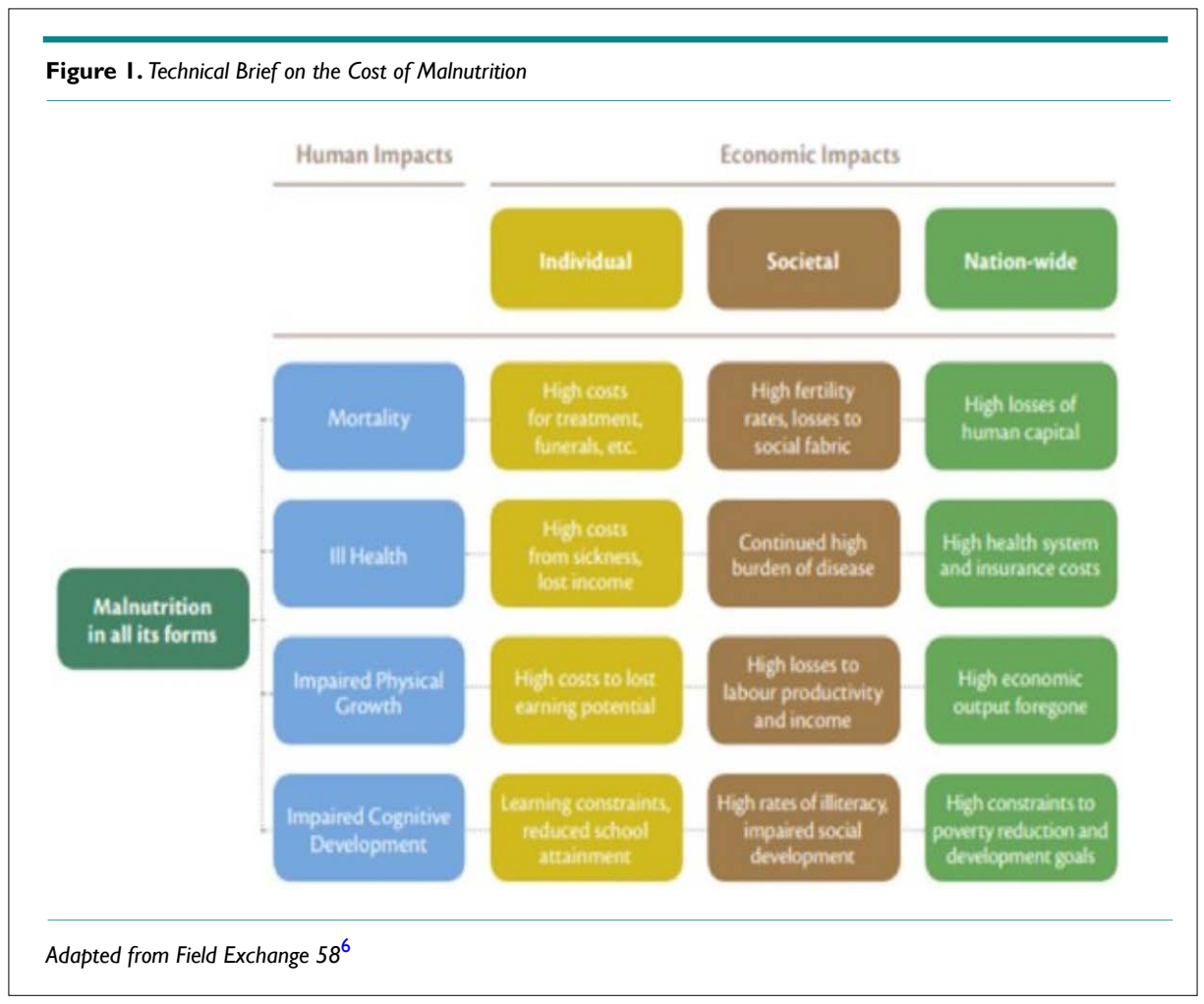

reduces attainment, resulting in lost employment and socialization opportunities throughout life.

In summary, malnutrition has an effect on human health and therefore on social and economic development of Africa.

\section{The African Development Bank Contribution}

In 2018, 58.7 million children in Africa were stunted, 13.8 million children were wasted and 9.7 million children were overweight. ${ }^{7}$ Africa represents the continent that is the most affected by the double or triple burden of malnutrition, as countries show a combination of undernutrition, micronutrient deficiencies and overweight/obesity. Of the 41 countries globally that struggle with all threeforms of malnutrition, 30 are in Africa. ${ }^{8}$ This triple burden of malnutrition will lead to an increase in non-communicable diseases, and associated health costs.

Sustainable Development Goal (SDG) 3 to ensure healthy lives and promote well-being for all, and in particular the goal 3.8 to achieve Universal Health Coverage (UHC), is closely linked to SDG 2 of ending hunger and all forms of malnutrition. Tackling malnutrition by integrating a package of cost-effective interventions that prevent and treat malnutrition into regular health care will help achieving UHC by reducing health costs. With returns of $\$ 16$ for every $\$ 1$ invested nutrition, ${ }^{9}$ this cost-effective nutrition related interventions should be scaled up in order to ensure healthy lives and improve the quality of life of the people of Africa, which is one of the Bank's High 5 areas.

Through the Bank's 2018-2025 Multi-Sectoral Nutrition Action Plan, the Bank is integrating nutrition in its agriculture, wa- ter and sanitation, education, social protection and health investment portfolio. The Bank supports the Government of Ethiopia in the roll out of its basic services transformation programme (BSTP), with particular focus on addressing quality and geographic inequalities in access to basic services in health, education, water and sanitation. The supplementary financing approved in November 2018 is allowing the Government to expand basic services mainly in the pastoral and underserved regions with emphasis on improving quality and equity for inclusive transformation.

\section{CONCLUSION}

Good nutrition is widely regarded as one of the key factors for advancing human well-being and economic prosperity. Undernutrition slows economic growth and deepens poverty through productivity losses from poor physical performance and cognitive capacity. ${ }^{2,10}$ It is important for African governments to promote agribusiness entrepreneurship to improvenutrition security and address the high-levels of malnutrition. Multi-sectoral policies (gender, agriculture, social protection, early childhood development, education, water, and nutrition) that tackle the social determinants of health are needed to achieve nutrition security and therefore SDGs and Africa's social and economic development.

\section{DISCLAIMER |}

The article represents the author's personal opinions and not that of the Bank.

\section{CONFLICTS OF INTEREST}

The authors declare that they have no conflicts of interest. 


\section{REFERENCES}

1. World Health Organization (WHO). What is malnutrition Weba site. https://www.who.int/features/qa/malnutrition/en/. Accessed February 11, 2020.

2. Perez-Escamilla R, Bermudez O, Buccini GS, et al. Nutrition disparities and the global burden of malnutrition. BMJ. 2018; 361: k2252. doi: 10.1136/bmj.k2252

3. Food and Agriculture Organization (FAO). Pulses and the link between nutrition and health Web site. http://www.fao. org/pulses-2016/news/news-detail/en/c/386990/. Accessed February 11, 2020.

4. Mason JB, Shrimpton R, Saldanha U, et al. The first 500 days of life: policy to support maternal nutrition. Glob Health Action. 2014; 7: 23623. doi: 10.3402/gha.v7.23623

5. United Nations International Children's Emergency Fund (UNICEF), World Health Organization (WHO), World Bank Group (WBG). Joint child malnutrition estimates - Level and trends Web site. https://www.who.int/nutgrowthdb/estimates2016/en/. Accessed February 11, 2020.
6. Field Exchange 58 Web site. https://www.ennonline.net/ fex/58/technicalbriefcostofmalnutrition. Accessed February 11, 2020 .

7. United Nations International Children's Emergency Fund (UNICEF), World Health Organization (WHO), World Bank Group (WBG). Levels and trends in child malnutrition Web site. https://reliefweb.int/report/world/levels-and-trendschild-malnutrition-unicefwhoworld-bank-group-joint-childmalnutrition. Accessed February 11, 2020.

8. Hawkes C. Shining a light to spur action on nutrition Web site. https:/ / scalingupnutrition.org/news/the-2018-global-nutritionreport-shining-a-light-to-spur-action-on-nutrition/. Accessed February 11, 2020.

9. Shekar M, Kakietek J, Eberwein J, Walters D. Global investment framework for nutrition Web site. https://www.growgreat.co.za/ wp-content/uploads/2018/10/An-Investment-Framework-forNutrition..pdf. Accessed February 11, 2020.

10. Field Exchange. Technical brief on the cost of malnutrition Web site. https://www.ennonline.net/fex/58/ technicalbriefcostofmalnutrition. Accessed February 11, 2020. 